\title{
Red ginseng spa therapy identification and preferences: targeting Chinese and Japanese tourists
}

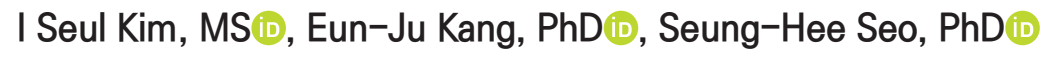 \\ Department of Cosmetology, Dongshin University, Naju, Rep. of Korea
}

\begin{abstract}
Background: The spa tourism industry taking on national dimensions, as competition in investment strengthens competitiveness, but research on development of spa therapies with Korean characteristics is lacking.

Objective: This study examined red ginseng spa perceptions and preferences of foreign visitors to Korea, to provide basic material to develop a Korean spa program aimed at developing the beauty tourism industry.

Methods: The study method involved a survey of a sample of Japanese and Chinese tourists who visited red ginseng spas. In total, 359 questionnaires were used in the final analyses.

Results: Chinese tourists ranked excellent effects following therapy and diverse therapy programs first, while Japanese tourists ranked large differences in quality of therapy goods first. With respect to the appropriate time required for red ginseng spa therapy, both Chinese and Japanese tourists preferred two hours. Regarding red ginseng therapy programs, the proportions of Chinese who preferred red ginseng whole body oil massage and red ginseng facial massage were $38.5 \%$ and $34.8 \%$, respectively, while the proportions of Japanese who preferred red ginseng facial massage and red ginseng head massage were $39.2 \%$ and $31.4 \%$, respectively. Both Chinese and Japanese tourists were satisfied with the use of red ginseng oil as the highest rated cosmetic following red ginseng spa therapy.

Conclusion: If tourist products are developed, and multidimensional follow-up research is performed by heightening perceptions and preferences concerning spa programs, based on the above study results, it will contribute to the development of Korean-style spa programs that are competitive on the global market.
\end{abstract}

Keywords: Chinese tourists; Japanese tourists; red ginseng; spa program; spa therapy

\section{Introduction}

With an increasing standard of living due to advancements in industry, the world tourism industry is developing rapidly with changes in personal income and consumption structure. The international tourism industry is growing continuously, reaching nearly 1.08 billion in 2013. According to the United Nations World Tourism Organization (UNWTO), international tourist will reach 1.8 billion annually by 2020 [1]. Along with the development of the tourism industry itself, the beauty industry has brought about the expansion of tourism at a faster pace than the development of the global economy, which has also influenced the increase in the number of visitors to Korea. This signifies that the Korean beauty (K-Beauty) industry is becoming a new blue ocean market in the tourism industry. Thanks to the effect of the Hallyu (Korean Wave), there has been a recent increase in foreigners' cultural interest in Korea. There is a rising number of K-Beauty tourists wishing to receive aesthetic

Received December 13, 2019; Revised December 24, 2019; Accepted December 26, 2019

Corresponding author: Seung-Hee Seo

E-mail: ssh@dsu.ac.kr

This is an Open Access article distributed under the terms of the Creative Commons Attribution Non-Commercial License (http://creativecommons.org/licenses/by-nc/4.0), which permits unrestricted non-commercial use, distribution, and reproduction in any medium, provided the original work is properly cited.

Copyright @ 2019 Korean Society of Korean Cosmetic Surgery and Medicine (KSKCS \& KCCS). 
treatments, especially from the Asian region including Japan and China. This opens up great possibilities for the popularization of the K-Beauty industry. In particular, the spa tourism industry is developing into a national-level industry with eager investors strengthening competitiveness. Consumer interest is being piqued through health tourism, the pursuit of a "wellness lifestyle," or beauty tourism for rest and relaxation. Early Korean spas initially offered additional skincare by providing functional bathtubs in skincare centers developed since the early 1980s. Since the early 1990s, this was a leisure activity enjoyed by only a select few. However, with recent changes in consumer trends and perceptions through the media, it is becoming popularized. Furthermore, combined therapy centers that combine various programs such as hydrotherapy, oriental therapy, thalassotherapy, aromatherapy, color therapy, and sound therapy have been a recent trend, as many well-known spa brands from overseas have entered the Korean market [2]. According to the "2011 Foreign Visitors Status Report," hot springs and spas were more popular than beauty and medical tourism among major tourism activities and were predicted to have prospects as a 21stcentury industry based on recognition of their diversity [3].

Red ginseng refers to fresh yellow-brown or red-brown sixyear-old ginseng produced through the process of washing, steaming, and drying without removal of the skin [4]. Saponin, a natural surfactant that produces bubbles, is generated in the process of producing red ginseng from ginseng. According to data from the Ministry of Food and Drug Safety (2002), red ginseng-related products comprised the largest portion of health food products at $52.6 \%$ of the total market in 2011 [5]. Red ginseng has superb effects, recognized mainly through forms such as concentrates, energy enhancers, and supplements. They include effects on blood circulation, high blood pressure improvement, anti-aging, anti-fatigue, prevention of diabetes, anemia improvement, cancer-fighting, and cancer-preventing effects, women's health, immunity improvement, and antioxidation. Based on such medical effects of red ginseng, ginseng is being used in various areas, including in the development of functional food products and Oriental medicine-based cosmetics. Among them, bath products made with red ginseng concentrates are popular in the spa and aesthetics industry. By bathing, the body is warmed, and the parasympathetic nervous system of the autonomic nervous system is stimulated, resulting in effects such as improvement in blood circulation, edema, fatigue, cold feet and hands, and muscle relaxation [6].

The term "spa" originates in Spau, a Belgian town famous for its natural hot springs with excellent healing effects [2]. In the Latin idiom, "Salus per aquae," "Salus" means "health," "per" means "path," and "aque" means "water." Together, they mean "health by water," or "health through water" [7]. In other words, a spa stimulates the body's meridians, using the water's temperature and buoyancy, along with massage. It includes diverse elements such as nutrition, touch, aesthetics, movement, and healing through the elements of water, along with bath and beauty facilities. In addition, it signifies various therapies that help with relaxation and improvement in health and beauty [8].

Despite rapid advancements in the spa industry in the culture of people today, there is a lack of current research on the development of spa programs with Korean characteristics to lead the beauty tourism industry. Therefore, this study presents the need to develop spa programs that capture the characteristics of Korea for tourists visiting Korea. Tourists' perceptions and preferences concerning spa therapy using red ginseng, which can be easily obtained in Korea and is familiar to the public, were examined.

\section{Materials and methods}

\section{Research subjects}

The subjects of this study were Japanese and Chinese tourists visiting two G Spa locations that use red ginseng. Surveys were conducted from June 3, 2016 to July 3, 2016. A total of 400 surveys were distributed. After excluding incomplete surveys, 359 surveys were used in the final analyses.

\section{Survey and contents}

For the empirical analyses in this study, survey items from previous studies conducted by Choi [9], Park [3], and Lee [10] were revised, supplemented, and used. The self-report method was used for all items to measure the variables. Survey items were comprised of six items on general characteristics, three

Table 1. Survey contents

\begin{tabular}{lll}
\hline \multicolumn{1}{c}{ Item } & \multicolumn{1}{c}{ Survey content } & No. of items \\
\hline General characteristics & Sex, age, marital status, education level, monthly income, job & 6 \\
Red ginseng spa perception & Red ginseng spa information, red ginseng spa selection criteria, red ginseng spa effects & 3 \\
Red ginseng spa preference & $\begin{array}{l}\text { Differences in red ginseng spas, duration, cost of care, preferred pressure, red ginseng care } \\
\text { program, satisfaction with cosmetics }\end{array}$ & 6 \\
\hline
\end{tabular}


items on perception of red ginseng spas, and six items on preferences for red ginseng spas, for a total of 15 items. The specific details of the items are shown in Table 1.

\section{Results}

\section{General characteristics}

Looking at the nationality frequencies, $48.2 \%$ of all respondents were Chinese, and $51.8 \%$ were Japanese (Table 2). The results of examining the general characteristics are shown in Table 3. With respect to sex, $97.1 \%$ of the Chinese tourists were

Table 2. Nationality frequency

\begin{tabular}{ccc}
\hline Category & Frequency (n) & Percentage \\
\hline Nationality & & \\
Chinese & 173 & 48.2 \\
Japanese & 186 & 51.8 \\
Total & 359 & 100.0 \\
\hline
\end{tabular}

female, while $2.9 \%$ were male. A total of $98.9 \%$ of Japanese tourists were female, while $1.1 \%$ were male. Among both Chinese and Japanese tourists, the proportion of women who use red ginseng spas was higher. In terms of age, more than half (62.4\%) of the Chinese tourists were "between 30 and 39," while the ages of the Japanese tourists were evenly distributed as follows: $38.2 \%$ were "between 30 and 39," 25.8\% were "between 50 and 59 ," and $17.7 \%$ were "between 40 and 49 " $\left(\chi^{2}=46.146, \mathrm{p}<0.001\right)$. For marital status, $81.5 \%$ of Chinese tourists and $87.6 \%$ of Japanese tourists were "married." For education level, the largest proportion of Chinese tourists (50.3\%) responded with "4-year college graduation," while a large proportion of Japanese tourists $(41.9 \%)$ responded with "professional school graduation" $\left(\chi^{2}=23.405, \mathrm{p}<0.001\right)$. Monthly income was most frequently "between 2.5 million Korean won (KRW) and 3 million KRW" (45.7\%), followed by “3 million KRW or above” (22.5\%) among Chinese tourists, while it was most frequently " 1.5 million KRW or below" (33.9\%), followed by "between 2.5 million KRW and

Table 3. General characteristics

\begin{tabular}{|c|c|c|c|c|c|}
\hline \multicolumn{2}{|r|}{ Category } & \multirow{2}{*}{$\begin{array}{l}\text { Chinese } \\
168(97.1)\end{array}$} & \multirow{2}{*}{$\begin{array}{c}\text { Japanese } \\
184(98.9)\end{array}$} & \multirow{2}{*}{$\begin{array}{c}\text { Total } \\
352(98.1)\end{array}$} & \multirow{2}{*}{$\frac{\chi^{2}(\mathrm{p} \text {-value })}{1.544(0.214}$} \\
\hline Sex & Female & & & & \\
\hline & Male & $5(2.9)$ & $2(1.1)$ & $7(1.9)$ & \\
\hline \multirow[t]{5}{*}{ Age (yr) } & Between 20 and 29 & $29(16.8)$ & $19(10.2)$ & $48(13.4)$ & $46.146^{* * *}(0.000)$ \\
\hline & Between 30 and 39 & $108(62.4)$ & $71(38.2)$ & $179(49.9)$ & \\
\hline & Between 40 and 49 & $4(2.3)$ & $33(17.7)$ & $37(10.3)$ & \\
\hline & Between 50 and 59 & $30(17.3)$ & $48(25.8)$ & $78(21.7)$ & \\
\hline & Between 60 and 69 & $2(1.2)$ & $15(8.1)$ & $17(4.7)$ & \\
\hline \multirow[t]{2}{*}{ Marital status } & Single & $32(18.5)$ & $23(12.4)$ & $55(15.3)$ & $2.597(0.107)$ \\
\hline & Married & $141(81.5)$ & $163(87.6)$ & $304(84.7)$ & \\
\hline \multirow[t]{4}{*}{ Education level } & High school graduation or below & $27(15.6)$ & $41(22.0)$ & $68(18.9)$ & $23.405^{* * *}(0.000)$ \\
\hline & Professional school graduation & $50(28.9)$ & $78(41.9)$ & $128(35.7)$ & \\
\hline & 4-year college graduation & $87(50.3)$ & $48(25.8)$ & $135(37.6)$ & \\
\hline & Graduate school or above & $9(5.2)$ & $19(10.2)$ & $28(7.8)$ & \\
\hline \multirow[t]{5}{*}{ Monthly income } & 1.5 million KRW or below & $18(10.4)$ & $63(33.9)$ & $81(22.6)$ & $45.778^{* * *}(0.000)$ \\
\hline & Between 1.5 million KRW and 2 million KRW & $6(3.5)$ & $15(8.1)$ & $21(5.8)$ & \\
\hline & Between 2 million KRW and 2.5 million KRW & $31(17.9)$ & $42(22.6)$ & $73(20.3)$ & \\
\hline & Between 2.5 million KRW and 3 million KRW & $79(45.7)$ & $49(26.3)$ & $128(35.7)$ & \\
\hline & 3 million KRW or above & $39(22.5)$ & $17(9.1)$ & $56(15.6)$ & \\
\hline \multirow[t]{6}{*}{ Job } & Student & $0(0.0)$ & $14(7.5)$ & $14(3.9)$ & $46.821^{* * *}(0.000)$ \\
\hline & Housewife & $16(9.2)$ & $60(32.3)$ & $76(21.2)$ & \\
\hline & Self-employed & $21(12.1)$ & $17(9.1)$ & $38(10.6)$ & \\
\hline & Professional & $65(37.6)$ & $45(24.2)$ & $110(30.6)$ & \\
\hline & Service & $57(32.9)$ & $41(22.0)$ & $98(27.3)$ & \\
\hline & Other & $14(8.1)$ & $9(4.8)$ & $23(6.4)$ & \\
\hline Total & & $173(100.0)$ & $186(100.0)$ & $359(100.0)$ & \\
\hline
\end{tabular}

Values are presented as $\mathrm{n}(\%)$.

KRW, Korean won.

${ }^{* * *} \mathrm{p}<0.001$. 
3 million KRW" (26.3\%) and "between 2 million KRW and 2.5 million KRW" (22.6\%) among Japanese tourists $\left(\chi^{2}=45.778\right.$, $\mathrm{p}<0.001)$. While jobs were most frequently "Professional" (37.6\%) and "Service" (32.9\%) among Chinese tourists, jobs were most frequently "Housewife" (32.3\%), followed by "Professional" (24.2\%) and "Service" (22.0\%), among Japanese tourists $\left(\chi^{2}=46.821, \mathrm{p}<0.001\right)$.

\section{Comparison of perceptions of red ginseng spas}

The results of comparing perceptions of red ginseng spas are shown in Table 4 . The paths to obtaining information about red ginseng spas for Chinese tourists were "Travel agency" for $35.3 \%$ and "Referral from friends and family" for $23.1 \%$. For Japanese tourists, the paths to obtaining information were "Internet" for $38.7 \%$ and "Referral from friends and family" for $33.3 \%\left(\chi^{2}=45.446, \mathrm{p}<0.001\right)$. For main factors that affect red ginseng spa selection, $26.0 \%$ of Chinese tourists responded with "Location," 22.5\% responded with "Popularity," and $20.8 \%$ responded with "Spa with simple reservation process." A total of 28.5\% of Japanese tourists responded with "Popularity," $18.3 \%$ responded with "Service," and 17.2\% responded with "Location" $\left(\chi^{2}=25.939, \mathrm{p}<0.01\right)$. The most frequently cited effect of a red ginseng spa was "stress relief" for both Chinese and Japanese tourists (32.2\% and $26.7 \%$, respectively).

\section{Comparison of preferences in red ginseng spas}

The results of comparing preferences in red ginseng spas are shown in Table 5. For differences between red ginseng spas and regular spas, Chinese tourists most frequently cited "Excellent effects after care" and "Diverse care programs" (24.4\% each). Japanese tourists most frequently cited "Large differences in quality of care goods" (29.6\%). It was found that Japanese and Chinese tourists had different preferences for products. In terms of the appropriate time required for red ginseng spa care per session, both Chinese and Japanese tourists most frequently responded with "About two hours" (52.0\% and 54.8\%, respectively). In terms of appropriate cost of care per session, most Chinese tourists $(74.0 \%)$ responded with "Between 100,000 KRW and 200,000 KRW." A total of $54.8 \%$ of Japanese tourists responded with "Between 100,000 KRW and 200,000 KRW," while $27.4 \%$ responded with "Below 100,000 KRW," and $17.7 \%$ responded with "Between 200,000 KRW and 300,000 KRW" $\left(\chi^{2}=26.646, \mathrm{p}<0.001\right)$. Choi [9] found that the duration of each spa session was between one hour and 1.5 hours and that the mean cost of one spa session was below 100,000 KRW, showing some differences from the results of this study. The preferred pressure during red ginseng spa therapy was "Medium pressure" for both Chinese and Japanese tourists $(74.0 \%$ and $61.8 \%$, respectively), but Japanese tourists also often (27.4\%) respond-

Table 4. Comparison of red ginseng spa perceptions

\begin{tabular}{|c|c|c|c|c|c|}
\hline \multicolumn{2}{|c|}{ Category } & \multirow{2}{*}{$\begin{array}{l}\text { Chinese } \\
61(35.3)\end{array}$} & \multirow{2}{*}{$\begin{array}{r}\text { Japanese } \\
32(17.2)\end{array}$} & \multirow{2}{*}{$\begin{array}{c}\text { Total } \\
93(25.9)\end{array}$} & \multirow{2}{*}{$\begin{array}{c}\chi^{2}(\mathrm{p} \text {-value }) \\
45.446^{* * *}(0.000)\end{array}$} \\
\hline Path to obtaining information & Travel agency & & & & \\
\hline & Referral from friends and family & $40(23.1)$ & $62(33.3)$ & $102(28.4)$ & \\
\hline & Mass media & $10(5.8)$ & $11(5.9)$ & $21(5.8)$ & \\
\hline & Internet & $29(16.8)$ & $72(38.7)$ & $101(28.1)$ & \\
\hline & Other & $33(19.1)$ & $9(4.8)$ & $42(11.7)$ & \\
\hline \multirow[t]{8}{*}{ Factors that affect selection } & Location & $45(26.0)$ & $32(17.2)$ & $77(21.4)$ & $25.939 * *(0.001)$ \\
\hline & Price & $29(16.8)$ & $24(12.9)$ & $53(14.8)$ & \\
\hline & Popularity & $39(22.5)$ & $53(28.5)$ & $92(25.6)$ & \\
\hline & Excellent therapy technique & $5(2.9)$ & $1(0.5)$ & $6(1.7)$ & \\
\hline & Service & $13(7.5)$ & $34(18.3)$ & $47(13.1)$ & \\
\hline & Spa with good consultation & $5(2.9)$ & $17(9.1)$ & $22(6.1)$ & \\
\hline & Spa with good facilities & $1(0.6)$ & $0(0.0)$ & $1(0.3)$ & \\
\hline & Spa with simple reservation process & $36(20.8)$ & $25(13.4)$ & $61(17.0)$ & \\
\hline \multirow[t]{6}{*}{ Effect (multiple selection, total $[\mathrm{n}]=691$ ) } & Effect on various illnesses & $8(3.3)$ & $15(3.4)$ & $23(3.3)$ & - \\
\hline & Skin beauty effect & $51(20.8)$ & $110(24.7)$ & $161(23.3)$ & \\
\hline & Obesity treatment effect & $31(12.7)$ & $77(17.3)$ & $108(15.6)$ & \\
\hline & Stress relief & $79(32.2)$ & $119(26.7)$ & $198(28.7)$ & \\
\hline & Rest and revitalization & $66(26.9)$ & $97(21.7)$ & $163(23.6)$ & \\
\hline & Other & $10(4.1)$ & $28(6.3)$ & $38(5.5)$ & \\
\hline
\end{tabular}

Values are presented as $\mathrm{n}(\%)$.

-, not available.

${ }^{* *} \mathrm{p}<0.01,{ }^{* * *} \mathrm{p}<0.001$. 
Table 5. Comparison of red ginseng spa preferences

\begin{tabular}{|c|c|c|c|c|}
\hline Category & Chinese & Japanese & Total & $\chi^{2}(\mathrm{p}$-value $)$ \\
\hline $\begin{array}{l}\text { Differences between red ginseng spas and regular spas } \\
\text { (multiple selection, total }[\mathrm{n}]=741 \text { ) }\end{array}$ & & & & - \\
\hline Excellent effects after care & $81(24.4)$ & $113(27.6)$ & $194(26.2)$ & \\
\hline Large differences in quality of care goods & $66(19.9)$ & $121(29.6)$ & $187(25.2)$ & \\
\hline Diverse care programs & $81(24.4)$ & $89(21.8)$ & $170(22.9)$ & \\
\hline Diverse care methods & $50(15.1)$ & $42(10.3)$ & $92(12.4)$ & \\
\hline Professional and systematic knowledge of employees & $54(16.3)$ & $29(7.1)$ & $83(11.2)$ & \\
\hline There is not much of a difference & $0(0.0)$ & $15(3.7)$ & $15(2.0)$ & \\
\hline Appropriate time required for red ginseng spa care & & & & $1.907(0.592)$ \\
\hline Under 1 hour & $47(27.2)$ & $52(28.0)$ & $99(27.6)$ & \\
\hline About 2 hours & $90(52.0)$ & $102(54.8)$ & $192(53.5)$ & \\
\hline About 3 hours & $36(20.8)$ & $31(16.7)$ & $67(18.7)$ & \\
\hline About 4 hours & $0(0.0)$ & $1(0.5)$ & $1(0.3)$ & \\
\hline Appropriate cost of care & & & & $26.646^{* * *}(0.000)$ \\
\hline Below 100,000 KRW & $12(6.9)$ & $51(27.4)$ & $63(17.5)$ & \\
\hline Between 100,000 KRW and 200,000 KRW & $128(74.0)$ & $102(54.8)$ & $230(64.1)$ & \\
\hline Between 200,000 KRW and 300,000 KRW & $33(19.1)$ & $33(17.7)$ & $66(18.4)$ & \\
\hline Preferred pressure & & & & $11.268^{*}(0.010)$ \\
\hline Weak pressure & $17(9.8)$ & $13(7.0)$ & $30(8.4)$ & \\
\hline Medium pressure & $128(74.0)$ & $115(61.8)$ & $243(67.7)$ & \\
\hline Strong pressure & $25(14.5)$ & $51(27.4)$ & $76(21.2)$ & \\
\hline Very strong pressure & $3(1.7)$ & $7(3.8)$ & $10(2.8)$ & \\
\hline Red ginseng care program (multiple selection, total $[n]=682$ ) & & & & - \\
\hline Red ginseng facial massage & $113(34.8)$ & $140(39.2)$ & $253(37.1)$ & \\
\hline Red ginseng whole body oil massage & $125(38.5)$ & $96(26.9)$ & $221(32.4)$ & \\
\hline Whole body dry massage & $1(0.3)$ & $1(0.3)$ & $2(0.3)$ & \\
\hline Red ginseng head massage & $82(25.2)$ & $112(31.4)$ & $194(28.4)$ & \\
\hline Red ginseng whole body spa & $1(0.3)$ & $0(0.0)$ & $1(0.1)$ & \\
\hline Red ginseng body pack & $3(0.9)$ & $8(2.2)$ & $11(1.6)$ & \\
\hline Satisfactory cosmetics during care (multiple selection, total $[\mathrm{n}]=741$ ) & & & & - \\
\hline Red ginseng oil & $95(26.3)$ & $91(23.9)$ & $186(25.1)$ & \\
\hline Red ginseng essentials (skin, lotion) & $75(20.8)$ & $68(17.9)$ & $143(19.3)$ & \\
\hline Red ginseng essence & $64(17.7)$ & $67(17.6)$ & $131(17.7)$ & \\
\hline Red ginseng cream & $42(11.6)$ & $64(16.8)$ & $106(14.3)$ & \\
\hline Red ginseng pack & $6(1.7)$ & $5(1.3)$ & $11(1.5)$ & \\
\hline Red ginseng head products & $79(21.9)$ & $85(22.4)$ & $164(22.1)$ & \\
\hline Total & $173(100.0)$ & $186(100.0)$ & $359(100.0)$ & \\
\hline
\end{tabular}

Values are presented as $\mathrm{n}(\%)$.

KRW, Korean won; -, not available.

${ }^{*} \mathrm{p}<0.05,{ }^{* * *} \mathrm{p}<0.001$.

ed with "Strong pressure" $\left(\chi^{2}=11.268, \mathrm{p}<0.05\right)$. For red ginseng spa care programs, Chinese tourists frequently cited "Red ginseng whole body oil massage" (38.5\%) and "Red ginseng facial massage" (34.8\%). Japanese tourists frequently cited "Red ginseng facial massage" (39.2\%) and "Red ginseng head massage" (31.4\%). For satisfactory cosmetics after red ginseng spa care, both Chinese and Japanese tourists most frequently cited "red ginseng oil" (26.3\% and $23.9 \%$, respectively).

\section{Discussion}

The purpose of this study was to perform comparative analyses of perceptions and preferences concerning spa therapy using red ginseng among tourists visiting Korea and to provide 
basic data for the development of a Korean spa program for advancements in the beauty tourism industry. The conclusions of this study are as follows.

For both Chinese and Japanese tourists, the most cited effect of red ginseng spas was "stress relief." Based on these results, a synergic effect is possible to improve the satisfaction of visitors to Korea with therapy if a red ginseng healing program that combines stress-focused therapy or various spa therapies using red ginseng products can be developed.

The results of examining preferences in red ginseng spas among Chinese and Japanese tourists showed that Chinese tourists preferred "Excellent effects after care" and "Diverse care programs" as differences between red ginseng spas and regular spas. This shows that tourists visiting Korea want to relieve stress using travel or spa and think of it as a means of spending leisure time. Furthermore, the effect of red ginseng is perceived to be high, and general satisfaction with red ginseng spas is shown to be high. Japanese tourists responded with "Large differences in quality of care goods." In other words, the results imply that the use of red ginseng makeup can contribute to satisfaction with a visit and intent to revisit more than other methods in marketing strategies for Japanese tourists. For example, if an explanation about the cosmetics used during aftercare treatment is given, unused cosmetics are presented, product recommendations for the client are made, or samples of red ginseng cosmetics with personalized characteristics for the client are gifted, sales of red ginseng makeup and spa utilization can be increased. The appropriate time required for red ginseng spa care per session was most frequently "About two hours" for both Chinese and Japanese tourists, while both Chinese and Japanese tourists preferred "Between 100,000 KRW and 200,000 KRW" as the appropriate cost of care per session. The appropriate time required for red ginseng spa care may have been affected by the mean duration of care in existing spa brands. Duration of care is subdivided into 60, 90, 120 minutes, and 180 minutes. Among these, the most preferred duration is 120 minutes, or "About two hours." Therefore, it is inferred that marketing advertisements such as diverse events and discounts for the price of programs that fit the characteristics of visitors to Korea can be effective in increasing spa brand sales and profits. For red ginseng spa care programs, Chinese tourists preferred "Red ginseng whole body oil massage," while Japanese tourists preferred "Red ginseng facial massage." In terms of satisfactory cosmetics used during care, Chinese tourists and Japanese tourists both preferred "red ginseng oil". Based on these results, a program in which clients can experience whole body oil massage and red ginseng facial massage together within a limited timeframe are suggested. There were significant differences between Chinese tourists and Japanese tourists in terms of perceptions and preferences concerning red ginseng spas. Based on its findings, this study aims to provide basic data for the development of spa programs that consider tourist characteristics. A program that uses massage therapies that combine health food products (in which the effect of red ginseng can be found), red ginseng concentrate bath products, and red ginseng oil for Chinese tourists and a program that uses the functions and diversity of red ginseng cosmetics for Japanese tourists can greatly contribute to developing a more specialized Korean spa program and tourism products.

\section{Conflicts of interest}

The authors have nothing to disclose.

\section{References}

1. Kim BI, Kim MS, Jang TS, Choi SI, Kang SO, Hur EY, et al. Spa beauty therapy. Seoul: Jungdam Publishing Co.; 2006.

2. Moon YJ. A study on using possibility of Korean red ginseng residue extract in the food and pharmaceutical industry by analysis of ginsenosides and sensory characteristics [dissertation]. Seoul: Korea University; 2015.

3. Park YJ. A research on the level of satisfaction and utilization of Korean spas by Korean, Chinese, and Japanese tourists [dissertation]. Seoul: Konkuk University; 2014.

4. Park YI. The comparison of health management effects using Shiatsu therapy between Koreans and Japanese [dissertation]. Busan: Kosin University; 2013.

5. Park CS. Research of body improvement effects of Shiatsu treatment [dissertation]. Daejeon: Daejeon University; 2006.

6. Paek HY. Effect of red ginseng dose on female skin condition [dissertation]. Seoul: Konkuk University; 2013.

7. Shin YW. Public awareness of spa and their preferences for spa programs [dissertation]. Seoul: Chung-Ang University; 2014.

8. Yang S. An exploratory study of beauty tourism of Chinese visiting Korea [dissertation]. Seoul: Sookmyung Women's University; 2013.

9. Choi JA. A study on awareness and usage behavior of domestic spas, and current status of spa programs [dissertation]. Seoul: Dongduk Women's University; 2014.

10. Lee HY. A study on actual use of spa and their satisfaction [dissertation]. Seoul: Sungshin Women's University; 2011. 